\title{
Turkish validity and reliability of coronavirus anxiety scale
}

\author{
Nurten Arslan Işik ${ }^{1}$. Gülden Küçükakça Çelik ${ }^{2}$. Gülsün Ayran ${ }^{1}$ \\ Accepted: 18 November 2021 / Published online: 15 January 2022 \\ (c) The Author(s), under exclusive licence to Springer Science+Business Media, LLC, part of Springer Nature 2021
}

\begin{abstract}
The Coronavirus Anxiety Scale (CAS) was developed to differentiate individuals who were functionally impaired by anxiety about COVID-19 from those anxious, but not disabled by their emotional reactions to the disease. The aim of the present study is to validate the Turkish version of the CAS. The study was carried out in two stages. In the first phase, the validity and reliability study of the scale was conducted with 95 people. The single-factor structure of the scale was confirmed with exploratory factor analysis and confirmatory factor analysis results. Cronbach's alpha internal consistency coefficient was found to be 0.86 . In the second stage; the data were collected using the Turkish version of CASand Herth Hope scale. The scales were applied to 720 people. It was determined that there was a statistically significant relationship between total CAS scores and the Herth Hope Index. These findings revealed that the CAS was a valid and reliable measurement tool for evaluating the anxiety levels of individuals.
\end{abstract}

Keywords Anxiety $\cdot$ Coronavirus (COVID-19) $\cdot$ Mental health $\cdot$ Validity $\cdot$ Reliability

\section{Introduction}

COVID-19 is a type of virus from beta-coronavirus family including SARS-CoV and MERS-CoV. This virus appeared in Wuhan Province of China in 2019 and has affected the whole world in a very short time. It was declared as an international urgent public health problem by the World Health Organization (WHO) on 30 January 2020. As of 4 October 2021, 234609003 confirmed cases and 4797368 deaths were reported worldwide (WHO, 2021). The clinical features of COVID-19 can vary from asymptomatic to severe acute respiratory distress syndrome and multi-organ dysfunction. COVID-19 virus which causes respiratory infection not only threatens

Nurten Arslan Işik

nurtenarslanisik1@gmail.com

Gülden Küçükakça Çelik

guldenkucukakca@hotmail.com

Gülsün Ayran

gulsun_ayran@hotmail.com

1 Faculty of Health Sciences, Erzincan Binali Yıldırım University, Erzincan, Turkey

2 Selma Vefa Küçük Faculty of Health Sciences, Nevşehir Hacı Bektaşi Veli University, Nevşehir, Turkey physical health but also has both short and long-term effects upon the mental health (Almond \& Mazumder, 2005). The first COVID-19 case diagnosed in Turkey was announced by the Ministry of Health on 10 March 2020 (Şahin, 2020). With the increase at the number of cases, the government had to take many protective measures, especially obligatory quarantine as the leading, for the people turning back from abroad. Taking strict measures to reduce the risks and impact of the disease, the forced closure of schools and the suspension of all unnecessary production and commercial activities, separation from family members and friends, inability to meet daily needs, and salary cuts and social isolation increased the anxiety of people about how they would react individually and collectively (Lee, 2020; Taylor, 2019).

Pandemics are known to cause many psychological disorders such as anxiety, depression, and sleep disorders (Balaratnasingam \& Janca, 2006). People's mental health is negatively affected during the pandemic period due to the reasons such as desperation, obscurity, social isolation, restrictions and quarantine (Lee, 2020; Uysa \& Eren, 2020). As result of many studies, it has been observed that COVID-19 has created high level of psychological problems on people. For example, in a recent large-scale study upon people who were highly susceptible to coronavirus infection, the prevalence rate of traumatic stress 
was determined to be $73.4 \%$, depression prevalence was $50.7 \%$ and anxiety was determined to be $44.7 \% .36 .1 \%$ of the participants in the study stated that they had insomnia problems (Liu et al., 2020).

As result of the researchers carried out on the psychological effect of pandemics, it has been revealed that individuals have shown symptoms of pandemic anxiety, experienced contamination and health anxiety, and at the same time that these people have been considerably prone to commit suicide (Wheaton et al., 2012; Yip et al., 2010). Although the symptoms individuals have shown during COVID-19 pandemic have generally been similar to anxiety, the researchers have suggested that many people show symptoms of anxiety during viral pandemics (Asmundson \& Taylor, 2020; Lee, 2020). It has been reported in the literature that people have experienced extreme fear and anxiety about becoming infected despite taking safety precautions and obeying social distance rules, and have constantly been worried about family members who are sick or dying (Lee, 2020; Wang et al., 2020). In a previous study, it was reported that approximately $10 \%$ to $30 \%$ of the society was very worried about the possibility of contracting the virus during an influenza epidemic (Rubin et al., 2010).

People with high level of health anxiety are more sensitive to interpreting simple bodily symptoms. They constantly look for evidences that they are infected. Thus, the situations such as unnecessary occupation of health centers, excessive washing of hands and social withdrawal can have negative consequences for both the individual and the society in which they live. Misinterpreting harmless bodily symptoms or changes as signs of infection can cause people to worry and panic unnecessarily (Taylor, 2019). In a study carried out with 1,210 people in China in the first months of the pandemic, it was determined that whereas $13.8 \%$ of the participants had mild depressive symptoms, $4.3 \%$ had severe symptoms (Van Bortel et. al., 2016). In one study, those functionally affected by coronavirus anxiety showed more hopelessness, suicidal ideation, religious crises, and were engaged in alcohol and substances, compared to those who were not as affected (Lee, 2020).

Psychosocial evaluations must be handled carefully, with exposure to infected sources, such as family members, and loss of loved ones, This creates physical distance, economic loss, depression, psychosomatic symptoms, insomnia, and even domestic violence. Moreover, positive psychological forces that help individuals to cope with their anxieties should also be included in the psychosocial evaluation. For example, hope that is considered among the psychological strengths that individuals have enables people solve problems when they encounter with stressful situations and persist in crisis (Mirhosseini et al., 2020). Many studies in the literature have revealed that individuals with high level of hope tend to have better psychological, social and physical well-being, in general (Schofield et al., 2016; Wang et al., 2017). Therefore, hope is considered to be an important variable with a powerful effect in reducing anxiety. However, there is not enough information about the role of hope on the anxiety felt during the COVID-19 pandemic.

Health professionals must gauge patients' psychological function to help them manage high levels of anxiety. Although professionals are aware of growing fear and anxiety, they must use objective measures to assess it. In this regard, Lee (2020) developed the Coronavirus Anxiety Scale (CAS), with strong psychometric properties, that assess physiologically-based anxiety and information about the coronavirus. We found that the CAS can identify factors that exacerbate anxiety during the pandemic and allow us to plan psychosocial interventions in advance for at-risk groups.

The CAS measures individuals' physiologically-based reactions of fear and anxiety to coronavirus related information. It has solid psychometric properties and has been validated. It is believed that the CAS can help identify factors that influence fear during the pandemic period and plan psychosocial interventions for at-risk groups in advance. Thus, we aimed to validate the CAS, which was originally developed in English, in Turkish with Turkish adults.

\section{Methods}

\section{Participants and Procedure}

A cross-sectional research was carried out in MayAugust 2020 with the Turkish population residing in Turkey reached via electronic media. The survey link created through Google forms was sent to the participants via social media, WhatsApp groups and e-mail, and the participants were asked to fill out and share the survey link. In cultural adaptation studies, it is suggested for the sample size to be between 10 to 20 times more of the number of items in the scale in order to conduct psychometric analysis (Büyüköztürk, 2018). In order to carry out the validity and reliability study of the scale, the sample number and the number of items in the scale were $\times 19$, and 95 adults were reached.

When the COVID - 19 process is very challenging for the individual, discouraging and anxiety-inducing interruptions can occur. Hope, in times of depression and despair; energies and lives fuel efforts to rebuild and cope. For one needs support to endure long-term uncertainties (Walsh, 2020). Does holding on to hope in this process and maintaining hope in the midst of uncertainty affect the individual's level of anxiety and therefore their response to the anxiety scale? 
To answer this question, following the validity and reliability study of the CAS scale, 720 adult individuals were reached who had Internet access and volunteered to participate in the study, and they were asked to complete the CAS and Herth Hope scales.

\section{Data Collection Tools}

\section{Question Form}

This section included items questioning some of the sociodemographic characteristics of individuals and the coronavirus (COVID-19) pandemic process.

\section{Coronavirus Anxiety Scale -Turkish Version (CAS-Turkish Version)}

The Coronavirus Anxiety Scale (CAS) was developed by Sherman A. Lee (2020) to distinguish individuals who are functionally impaired by anxiety about COVID -19 from those who are anxious but not disabled by their emotional responses to the disease. The tool including five-point Likert type answer choices, was rated on a five-point scale from 0 (not at all) to 4 (almost every day) based on the experiences in the last two weeks. CAS cut-off score was 9. CAS total score of 9 indicated dysfunctional anxiety associated with coronavirus. Cronbach Alpha Reliability Coefficient of the scale was found to be 0.93 by Sherman A. Lee. In this study, cronbach's alpha internal consistency coefficient was found to be 0.86 . In the second application of the study conducted with different 720 people, the cronbach's alpha was determined as 0.87 . High scores on a particular item or high total scale score could indicate anxiety symptoms that required further evaluation or treatment of the individual (Lee, 2020).

\section{Herth Hope Scale}

The scale was developed by Dr. Herth in order to determine hope levels of individuals in (Herth, 1991), and the internal consistency coefficient was found to be 0.84 adapting the scale into Turkish by Aslan et al. (2006). It included totally 30 items. It was a four-point Likert-type scale that was answered as "I strongly disagree" (0 point), "I rarely agree" (1 point), "I sometimes agree" ( 2 points) and "I strongly agree" (3 points) for each item. The scale included 3 sub-dimensions as "Future," "Positive Readiness and Expectation" and "The Links between Himself and His Surroundings." High scores taken from the scale indicated that the level of hope was high, and the total score of the scale was obtained summing the scores given to all items, and the sub-dimension score was obtained summing the scores of the answers given to each subscale. The total score ranged from 0 to 90 , and the total score for each sub-dimension varied between 0 and 30 . The Cronbach alpha coefficient of the scale was found to be 0.84. In this study, the Cronbach alpha coefficient was determined to be 0.92 (Aslan et al., 2006).

\section{Data Analysis}

The data obtained in the study were analyzed using SPSS 25 and AMOS 21 package software. SPSS package software and item analysis were used for reliability analysis, explanatory factor analysis and confirmatory factor analysis with AMOS package software. "Cronbach alpha coefficient" was calculated for internal consistency for determining the level of reliability value of the developed scale. Exploratory Factor Analysis (EFA) was performed determine the construct validity of the scale, and Confirmatory Factor Analysis (CFA) was performed to test the confirmability of the structure appeared as result of EFA. Basic components technique was used to determine the factor structure. Bartlett test was used to decide whether the data were suitable for factor analysis, and Kaiser-Meyer-Olkin (KMO) test was used for sampling adequacy. Subsequently, confirmatory factor analysis was performed to test the construct validity. For the discrimination validity of the scale, the results of CR (Composite/Structure Reliability) and AVE (Average Variance Extracted) values were analyzed. Pearson Correlation analysis was used to determine the relationship between the two scales. The significance level was accepted as 0.05 .

\section{Results}

\section{Language Validity}

The original language of CAS scale is English. According to the author's knowledge, the scale has validity and reliability studies in 25 different languages. In language validity study of the CAS scale, the English text created by the author of the scale was used. The language validity process included the translation stages of the scale from English to Turkish and then from Turkish to English. In the first stage, the scale was translated from English to Turkish by 2 different linguists and an academician who knew both Turkish and English languages professionally. In the second stage, the scale, which was translated into Turkish, was combined into a single instrument combining three translations made by the committee including three members (three academic nurses with doctor titles) who knew both languages and reached an agreement on it. In the third stage, the text was translated into English by a native 
English translator who spoke both languages at the native level. The scale, which was translated back into English, was compared with the original English scale, no change in meaning was observed in the scale items and the language validity of the scale was completed.

\section{Content Validity}

Davis technique was used for the content validity of the scale. After comparing the retranslated scale with its English original, prepared Turkish version was assessed by five experts (4 Mental Health and Psychiatric Nursing and 1 Child Health and Diseases Nursing) in Turkey. Necessary changes were made regarding the grading criteria developed for the measurement value of each item, and the Turkish scale was finalized. According to the Davis technique, the experts scored the suitability of the items as (1) "not suitable," (2) "somewhat suitable," (3) "quite suitable" and (4) "very suitable." In this technique, the "content validity index" for the item was found to be 0.80 dividing the number of experts who marked (3) and (4) options by the total number of experts.

\section{Test-Retest Reliability}

Test-retest reliability was determined with Pearson's Multiplication of Moments Correlation technique. When the relationship between the scores obtained in the test and the retest was analyzed, it was found that the relationship between the two test scores (r:0.941) was positive and statistically significant $(\mathrm{p}<0.05)$. According to this, it was possible to mention that the scale was not changing against time and was usable. Kaiser-Meyer-Olkin (KMO) test was performed to test whether the sample size was suitable for factor analysis. KMO value was determined to be 0.861 as result of the analysis. In accordance with this result, it was concluded that the sampling adequacy was "sufficient" for the factor analysis. Furthermore, when Bartlett's Sphericity test results were analyzed, it was noticed that obtained chisquare value was acceptable $(\chi 2(10)=767.751 ; p<0.01)$ (Table 1).

The five -item tool which aimed to measure the anxiety level of individuals participating in the study was developed depending on a single theoretical dimension. Principal components analysis was chosen as the factorization method in order to reveal the factor pattern of the coronavirus anxiety scale. In exploratory factor analysis, factor load values were determined to be above 0.50 . Factor loads were found to be at the desired level and between 0.767 and 0.857 . The single factor explained $64.943 \%$ of the total variance. Within this framework, the contribution of a defined factor to the total variance was noticed to be sufficient. The
Table 1 Exploratory factor analysis results related to coronavirus anxiety scale $(\mathrm{N}=95)$

\begin{tabular}{lcl}
\hline & $\begin{array}{l}\text { Coronavirus anxiety } \\
\text { scale }\end{array}$ & $\begin{array}{l}\text { Total item } \\
\text { correlation }\end{array}$ \\
\hline Item 1 & 0.767 & 0.637 \\
Item 2 & 0.857 & 0.755 \\
Item 3 & 0.830 & 0.719 \\
Item 4 & 0.800 & 0.682 \\
Item 5 & 0.772 & 0.642 \\
Reliability & 0.864 & \\
Explained variance $(\%)$ & 64.943 & \\
Eigenvalue $(\Lambda)$ & 3.247 & \\
\hline
\end{tabular}

$\mathrm{KMO}=0.861 ; \quad \chi^{2(10)}=767.751 ; \quad$ Bartlett Test for Sphericity $(\mathrm{p})=0.000$

Table 2 Coronavirus anxiety scale first level multifactorial model confirmatory factor analysis fit indices $(\mathrm{N}=95)$

\begin{tabular}{llll}
\hline $\begin{array}{l}\text { Good- } \\
\text { ness of fit } \\
\text { criteria }\end{array}$ & Perfect fit criteria & $\begin{array}{l}\text { Acceptable fit } \\
\text { criteria }\end{array}$ & Research finding \\
\hline CMIN/Df & $0 \leq \chi^{2} / \mathrm{df} \leq 3$ & $3 \leq \chi^{2} / \mathrm{df} \leq 5$ & 2.306 \\
GFI & $\geq 0.90$ & $\geq 0.85$ & 0.987 \\
CFI & $\geq 0.95$ & $\geq 0.90$ & 0.991 \\
RMSEA & $\leq 0.05$ & $\leq 0.08$ & 0.060 \\
NFI & $\geq 0.95$ & $\geq 0.90$ & 0.985 \\
IFI & $\geq 0.95$ & $\geq 0.90$ & 0.991 \\
\hline
\end{tabular}

Brown and Cudeck, 1993; Meydan and Şeşen, 2011

reliability coefficient (0.864) of the answers given by the participants indicated that the scale had a high degree of reliability (Table 1).

According to the Confirmatory Factor Analysis, it was determined that the structural equation modeling results of the scale were significant at $\mathrm{p}=0.000$ level, and the scale was associated with five items that in the scale and the single factor scale structure (Table 2). It was noticed that the accepted values for fit indices were met in the fit index calculations. When looking at the goodness of fit indexes of the coronavirus anxiety scale according to the first level multi-factor analysis results, the indices were possible to be mentioned as an acceptable level with values of RMSEA 0.060; GFI 0.987; CFI 0.991; $\chi 22.306(\mathrm{p}=0.000)$ (Table 2).

The factor loads for the scale were presented in Table 3, and the model for the first-level confirmatory factor analysis of the coronavirus anxiety scale was presented in Fig. 1. As could be seen, factor loads varied between 0.682 and 0.839 . The factor loadings were noticed to be above 0.40 . It was a desired criterion for a factor load to be at least 0.40 (Erefe, 2002; Polit \& Beck, 2018). The combined 
Table 3 Factor loads obtained as result of the confirmatory factor analysis performed for coronavirus anxiety scale $(\mathrm{N}=95)$

\begin{tabular}{|c|c|c|c|}
\hline Factor & Factor loads & CR & AVE \\
\hline \multicolumn{4}{|l|}{ Coronavirus anxiety scale } \\
\hline 1. I felt dizziness or weakness when I read or listened to the news related to coronavirus & 0.682 & 0.920 & 0.597 \\
\hline 2. I had trouble in falling asleep or maintaining sleep because I thought of coronavirus & 0.839 & & \\
\hline $\begin{array}{l}\text { 3. I felt myself as paralyzed or frozen when I was subjected to the news about coronavirus or I thought about coro- } \\
\text { navirus }\end{array}$ & 0.788 & & \\
\hline 4. I lost my feeling of hunger when I was subjected to the news about coronavirus or I thought about coronavirus & 0.747 & & \\
\hline $\begin{array}{l}\text { 5. I felt dizziness or stomach problems when I was subjected to the news about coronavirus or I thought about } \\
\text { coronavirus }\end{array}$ & 0.686 & & \\
\hline
\end{tabular}

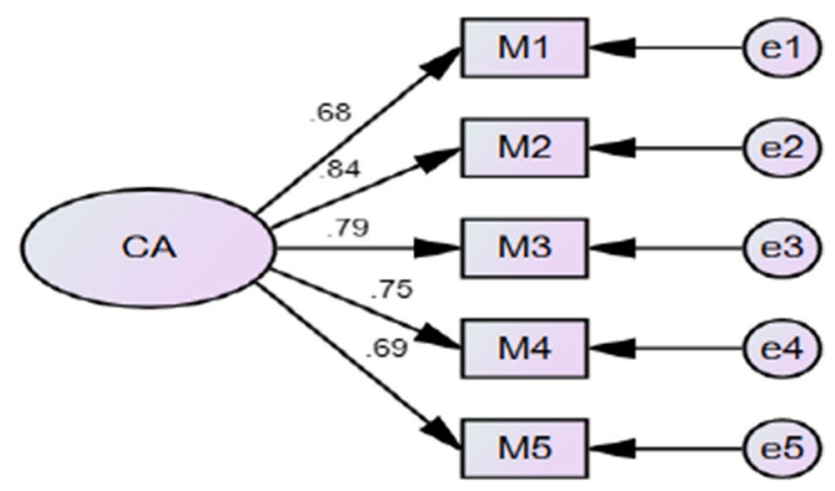

Fig. 1 The model related to the first level confirmatory multifactorial analysis of coronavirus anxiety scale

reliability value of the implicit variables in the measurement model should be higher than 0.70 , and the average explained variance value should be higher than 0.50 (Hair et al., 2010). As result, the scale was determined to have divergence validity.

In Table 4, Hope Index and Total CAS scores of the individuals and the distributions of the scales related to demographical features were presented. It was determined that the average age of the individuals participating in the study was $31.64 \pm 9.27$, the average number of people living at home was $3.78 \pm 1.62,67.6 \%$ were women, $56 \%$ were married, $50.6 \%$ did not have children, $63.2 \%$ were employed, $\% 85.7 \%$ of them did not have a chronic disease, $39.2 \%$ lived in the Eastern Anatolia Region, 52.5\% of them had equal income and expenditure, $99.3 \%$ of them were not diagnosed with COVID-19 and $97.1 \%$ of them did not have a family history of COVID-19 (Table 4).

Pearson correlation coefficient between the total score and subscale score from the Turkish Herth Hope scale, and the CAS scale were calculated as it was done in the original analysis of the CAS scale to support the construct validity. It was determined that there was a negative, and statistically significant relationship between the CAS total scores of the individuals who participated into the study and the future, positive readiness and expectation, the links between himself and his surroundings, and the Herth Hope scale $(\mathrm{p}<0.01)$.

\section{Discussion}

The worldwide pandemic of COVID-19 has rapidly and profoundly affected every aspect of daily life such as the way people work, live, shop, socialize and plan for their future, has caused panic and mental health problems for the public and is possible to increase anxiety symptoms worldwide (Fullana et al., 2020; Lee et al., 2020; Nguyen et al., 2020). For that reason, this study was carried out to determine the effect of COVID-19 pandemic that caused public health crisis on the mental health of the society and to adapt CAS into Turkish language, specify the scale's validity and reliability, and to determine the effect of coronavirus-related anxiety on the level of hope. When the findings were analyzed, it was determined that the validity-reliability criteria for the Turkish form of the scale were at an acceptable level (Table 5).

Kaiser-Meyer-Olkin (KMO) and Bartlett Sphericity tests were performed in order to test the suitability of the sample size for the factor analysis. Whereas the values between 0.5-1.0 were considered acceptable as KMO value, the values below 0.5 indicated that factor analysis was not suitable for the data set (Altunış1k et al., 2010). However, the minimum KMO value considered for a good factor analysis was expected to be higher than 0.8 (Anderson, 1988). The KMO coefficient of this study was found to be 0.86 (Table 1 ). The KMO value was found to be 0.88 in the 11-item COVID 19 Anxiety Syndrome scale developed by Nikčević and Spada (2020), and 0.88 in the 17-item Coronavirus Pandemic Anxiety Scale (Bernardo et al., 2020). The KMO coefficient in the original scale was determined to be 0.98 (Lee, 2020). The KMO value of the study in the original scale and other scales related to COVID 19 shows that the sample size is suitable for factor analysis. When Bartlett's test results were analyzed, it was noticed that obtained chi-square value was 
Table 4 Evaluating hope index and CAS total scores of the participants according to their demographical properties $(\mathrm{N}=720)$

\begin{tabular}{|c|c|c|}
\hline & $\mathrm{n}$ & $\%$ \\
\hline \multicolumn{3}{|l|}{ Gender } \\
\hline Female & 487 & 67.6 \\
\hline Male & 233 & 32.4 \\
\hline \multicolumn{3}{|l|}{ Marital status } \\
\hline Married & 403 & 56 \\
\hline Single & 307 & 42.6 \\
\hline Divorced & 10 & 1.4 \\
\hline \multicolumn{3}{|l|}{ Having a child } \\
\hline Yes & 356 & 49.4 \\
\hline No & 364 & 50.6 \\
\hline \multicolumn{3}{|l|}{ Status of employment } \\
\hline Yes & 455 & 63.2 \\
\hline No & 265 & 36.8 \\
\hline \multicolumn{3}{|l|}{ Having a chronic disease } \\
\hline Yes & 103 & 14.3 \\
\hline No & 617 & 85.7 \\
\hline \multicolumn{3}{|l|}{ Residential area } \\
\hline Eastern anatolian region & 282 & 39.2 \\
\hline Aegean region & 52 & 7.2 \\
\hline Marmara region & 96 & 13.3 \\
\hline Central Anatolia region & 113 & 15.7 \\
\hline Mediterranean region & 107 & 14.9 \\
\hline Black Sea region & 28 & 3.9 \\
\hline Southeastern anatolian region & 42 & 5.8 \\
\hline \multicolumn{3}{|l|}{ Level of Income } \\
\hline Income lower than expenditure & 145 & 20.1 \\
\hline Equal income and expenditure & 378 & 52.5 \\
\hline Income higher than expenditure & 197 & 27.4 \\
\hline \multicolumn{3}{|l|}{ Having COVID diagnosis } \\
\hline Yes & 5 & 0.7 \\
\hline No & 715 & 99.3 \\
\hline \multicolumn{3}{|l|}{ COVID history in family } \\
\hline Yes & 21 & 2.9 \\
\hline No & 699 & 97.1 \\
\hline Properties & $\mathrm{X} \pm \mathrm{SD}$ & \\
\hline Age (Year) & $31.64 \pm 9.27$ & \\
\hline Number of PEOPLE AT HOME & $3.78 \pm 1.62$ & \\
\hline
\end{tabular}

acceptable and statistically significant $(\chi 2(10)=767.751$; $\mathrm{p}<0.01$ ) (Table 1). This result proved that the sample size was sufficient for the factor analysis and the data were suitable for analysis (Büyüköztürk et al., 2008).

The five- item tool which aimed to measure the anxiety level of individuals who participated into the study was developed depending on a single theoretical dimension. Basic component analysis was chosen as the factorization method in order to reveal the factor pattern of the coronavirus anxiety scale. Although there was no definite limit
Table 5 Evaluating the correlation between CAS and Herth Hope Index subdimensions' total scores $(\mathrm{N}=720)$

\begin{tabular}{lll}
\hline Herth hope index & \multicolumn{2}{l}{ CAS } \\
\cline { 2 - 3 } & $\mathrm{r}$ & $\mathrm{p}$ \\
\hline Sub-dimension of future & -0.147 & $0.000^{* *}$ \\
$\begin{array}{l}\text { Sub-dimension of positive readiness and expecta- } \\
\text { tion }\end{array}$ & -0.029 & 0.439 \\
$\begin{array}{l}\text { Sub-dimension of the links between himself and } \\
\text { his surroundings }\end{array}$ & -0.097 & $0.009^{* *}$ \\
$\begin{array}{l}\text { Total } \\
* * *\end{array}$ & -0.103 & $0.006^{* *}$ \\
\hline Correlation is significant at 0.01 level (2-tailed) & &
\end{tabular}

in practice for the factor load value in the literature, items with a factor load of 0.40 and above were regarded and it was stated that the load values between 0.30 and 0.59 were medium and the values between 0.60 and above were high (Akgül, 2003; Aksakoğlu, 2001). According to the analysis results performed in this study, it was determined that the factor loads were between 0.767 and 0.857 and the factor load value was high.

It was found that the factor loads of all items were over 0.40 and high in the scale which included five items and one sub-dimension. As result of the analyzes, Cronbach Alpha coefficient was used to test the internal consistency of the items in CAS and the reliability of the scale. In the literature, it was reported that if the Cronbach Alpha coefficient was below 0.40, the scale was not reliable, if the value was between 0.40 and 0.59 , the scale had low reliability, if between 0.60 and 0.79 , this meant the scale had reliability and if between 0.80-100, this indicated high reliability (Knapp, 1998; Tavşanc1l, 2010). In this study, the reliability coefficient of the answers given by the participants was determined to be 0.864 (Table 1). The Cronbach Alpha Reliability Coefficient of the original scale was found to be 0.93 (Lee, 2020). In the developed COVID 19 Anxiety Syndrome Scale, the Cronbach Alpha Reliability Coefficient was found to be 0.86 (Nikčević \& Spada, 2020). It was found to be 0.87 in the Coronavirus Pandemic Anxiety Scale (Bernardo et al., 2020). According to these results, it was determined that the Cronbach Alpha Reliability Coefficient of the Turkish version of the CAI had high reliability.

The single factor that occurred explained $64.943 \%$ of the total variance (Table 1). In single factor designs, the value for the variance explained to be $30 \%$ or more was considered to be sufficient (Tavşanc1l, 2010). It explains $62.4 \%$ of the variance explained in the two-factor design in the developed COVID 19 Anxiety Syndrome Scale (Nikčević \& Spada, 2020). In the original scale, the single factor explained $59.85 \%$ of the total variance. Within this framework, it was 
noticed that the contribution of a defined factor upon the total variance was sufficient. The high variance ratios indicated that the factor structure of the scale was strong (Şencan, 2005).

The construct validity of the Coronavirus Anxiety Scale was evaluated with confirmatory factor analysis. Confirmatory Factor analysis was a method evaluating whether the results obtained from the data collected from the participants complied with the theoretical structure or not (Çapık, 2014). In this type of analysis, various fit indices such as Chi-square fit test (Chi-Square Goodness), GFI (Goodness of Fit Index), RMSEA (Root Mean Square Error of Approximation), CFI (Comparative Fit Index), NFI (Normed Fit Index), RFI (Relative Fit) Index) and IFI (Incremental Fit Index) were used. Among these indices, $p>0.05$ was required for the Chisquare fit test that regarded fit of the population covariance matrix and the sample covariance matrix. However, the $p$ value was generally significant because it was very sensitive to the sample size. In this case, the value ( $\chi 2 / \mathrm{df})$ obtained dividing the value of $\chi 2$ by the degrees of freedom was taken into account and this value should be 2 or less (Çapık, 2014; Waltz et al., 2010). In order to express that the model had a good fit, GFI, NFI and CFI values should be above 0.90 and the RMSEA fit test should be between 0 and 1 (Moon \& Kim, 2017). When CAS goodness of fit indices were analyzed, it was possible to mention that the model was at an acceptable level with the values of RMSEA 0.060; GFI 0.987, CFI 0.991 , and NFI 0.985 (Table 2).

It was a desired criterion for the factor load to be at least 0.40 (Erefe, 2002; Polit \& Beck, 2018). The combined reliability value of the implicit variables in the measurement model should be higher than 0.70 , and the average explained variance value should be higher than 0.50 (Hair et al., 2010). As result, it was determined that the scale had divergence validity (Table 3).

As the anxiety levels of the individuals in the study increase, their levels of hope decrease. Hope is a resilience factor that can improve well-being during a global health crisis (Gallagher \& Lopez, 2018). Individuals possessing more hope are less likely to have negative emotions and are more likely to adopt positive attitudes and coping strategies when faced with problems (Cheng et al., 2021).

When we look at studies concerning hope, the increase in the anxiety levels of individuals whose living conditions have changed during the coronavirus 2019 (COVID-19) pandemic process leads to a decrease in their hope levels (Erdoğdu et al., 2020; Hacimusalar et al., 2020; Bernardo \& Mendoza, 2020; Gallagher et al., 2021). Consistent with the literature, this study shows that hope and COVID-19 anxiety are important aspects of individuals' coping styles.

\section{Limitations of the Research}

This research has several limitations. Due to social distancing, the survey was spread online through social networks to reach a large research audience in a short time during the COVID-19 crisis. This type of online self response method may target specific socio-demographic groups. Because analyses of COVID-19 anxiety and hope levels are based on cross-sectional data, large-scale longitudinal or experimental studies in this population are needed to make comparisons between different future periods. These findings can be generalized to the research group because the COVID-19 process and its effects vary according to many factors, such as age, gender, socioeconomic and education levels, and region or country.

\section{Conclusions}

In conclusion, it was determined that "Coronavirus Anxiety Scale" which was developed on the basis of five items and single sub-dimension in order to determine the level of anxiety arisen from coronavirus pandemic was a valid and reliable measurement tool. Furthermore, in the study it was also found that as the anxiety levels of individuals increased, their level of hope decreased. It has been thought that the scale will contribute to further researchers to be carried out during the pandemic process and it is recommended to carry out more studies on the subject.

Data Availability The data that support the finding of this study are available from the corresponding author upon reasonable request.

\section{Declarations}

Disclosure Statement No potential conflict of interest was reported by the authors.

Ethical Principles of the Research In the study, necessary permission was obtained by e-mail from Sherman A. Lee, who developed the scale, in order to adapt the CAS into Turkish. In order to carry out the study, necessary permissions were obtained from the human researchers' ethics committee (Date: 30/04/2020 Protocol No: 04/24) and the Ministry of Health. A consent form including the information about the research was sent to the participants electronically, their consent was obtained and recorded.

\section{References}

Akgül, A. (2003). Statistical analysis techniques, SPSS applications in medical research (3rd ed.,pp.440-455). Emek Offset Ltd. Şti, Ankara. 
Aksakoğlu, G. (2001). Sağllkta araştırma teknikleri ve analiz yöntemleri (Research technics and analysis methods in health). Dokuz Eylül Üniversity Press.

Almond, D., \& Mazumder, B. (2005). The 1918 influenza pandemic and subsequent health outcomes: An analysis of SIPP data. American Economic Review, 95(2), 258-262. https://doi.org/ $10.1257 / 000282805774669943$

Altunışık, R., Çoşkun, R., Bayraktaroğlu, S. \& Yıldırım, E. (2010). Research Methods in Social Science. Sakarya Yayınc1lik.

Anderson, J. (1988). Content and text analysis. In: Keeves JP, Eds. Educational Research Methodology and Measurement. An International Handbook. Pergamon Press.

Aslan, O., Kamile, S., \& Akyol, M. (2006) Hope and learned resourcefulness among parents of disabled children. Nucleus, 98, 93-3. http://hdl.handle.net/10755/335179

Asmundson, G. J., \& Taylor, S. (2020). How health anxiety influences responses to viral outbreaks like COVID-19: What all decisionmakers, health authorities, and health care professionals need to know. Journal of Anxiety Disorders, 71(2), 1-2. https://doi.org/ 10.1016/j.janxdis.2020.102211

Balaratnasingam, S., \& Janca, A. (2006). Mass hysteria revisited. Current Opinion in Psychiatry, 19(2), 171-174. https://doi.org/10. 1097/01.yco.0000214343.59872.7a

Bernardo, A., \& Mendoza, N. (2020). Measuring hope during the COVID-19 outbreak in the Philippines: development and validation of the state locus-of-Hope scale short form in Filipino. Current Psychology, 1-10. https://doi.org/10.1007/ s12144-020-00887-x

Bernardo, A. B., Mendoza, N. B., Simon, P. D., Cunanan, A. L. P., Dizon, J. I. W. T., Tarroja, M. C. H., ... \& Saplala, J. E. G. (2020). Coronavirus pandemic anxiety scale (CPAS-11): development and initial validation. Current Psychology, 1-9. https://doi.org/ 10.1007/s12144-020-01193-2

Brown, M. W., \& Cudeck, R. (1993). Alternative ways of assessing model fit. Testing Structural Equation Models, 154, 136-162.

Büyüköztürk, Ş., Çokluk, Ö., \& Köklü, N. (2008). Statistics for social sciences. (3rd ed.) Pegem Publications.

Büyükoztürk, S. (2018). In Data analysis handbook for social science. Original work published in Turkish (Manual of data analysis for social sciences) (24 th. Ed.). Pegem Akademi Yayıncılık

Capik, C. (2014). Use of confirmatory factor analysis in validity and reliability studies. Journal of Anatolia Nursing and Health Sciences, 17(3), 196-205.

Cheng, L., Guo, X., Liu, H., Chen, Q., \& Cui, R. (2021). Hope, death anxiety and simplified coping style scores of nursing students during the outbreak of COVID-19: A cross-sectional study. Medicine, 100(34), e27016. https://doi.org/10.1097/MD.0000000000027016

Erdoğdu, Y., Koçoğlu, F., \& Sevim, C. (2020). An investigation of the psychosocial and demographic determinants of anxiety and hopelessness during COVID-19 pandemic. Journal Clinical Psychiatry, 23. https://doi.org/10.5505/kpd.2020.35403

Erefe, İ. (2002). Research and development methods in nursing, research principles, processes and methods in nursing. Odak Offset.

Fullana, M., Mazzei, D., Vieta, E., \& Radua, J. (2020). Coping behaviors associated with decreased anxiety and depressive symptoms during the COVID-19 pandemic and lockdown. Journal Affect Disorder, 1(275), 80-81. https://doi.org/10.1016/j.jad.2020.06.027

Gallagher, M., Smith, L., Richardson, A., D’Souza, J., \& Long, L. (2021). Examining the longitudinal effects and potential mechanisms of hope on COVID-19 stress, anxiety, and well-being. Cognitive Behaviour Therapy, 50(3), 234-245. https://doi.org/ 10.1080/16506073.2021.1877341

Hacimusalar, Y., Kahve, A., Yaşar, A., \& Aydın, M. (2020). Anxiety and hopelessness levels in COVID-19 pandemic: A comparative study of healthcare professionals and other community sample in
Turkey. Journal of Psychiatric Research, 129, 181-188. https:// doi.org/10.1016/j.jpsychires.2020.07.024

Hair, J., Black, W., Babin, B., \& Anderson, R. (2010). Multivariate data analysis (7th ed.). Prentice-Hall.

Herth, K. (1991). Development and refinement of an instrument to measure hope. Research and Theory for Nursing Practice, 5(1), 39.

Knapp, T. R. (1998). Quantitative nursing research. Sage Publications.

Lee, S. (2020). Coronavirus anxiety scale: A brief mental health screener for COVID-19 related anxiety. Death Studies, 44(7), 393-401. https://doi.org/10.1080/07481187.2020.1748481

Lee, S., Mathis, A., Jobe, M., \& Pappalardo, E. (2020). Clinically significant fear and anxiety of COVID-19: A psychometric examination of the Coronavirus Anxiety Scale. Psichiatry Research, 290, 1-7. https://doi.org/10.1016/j.psychres.2020.113112

Liu, S., Yang, L., Zhang, C., Xiang, Y., Liu, Z., Hu, S., \& Zhang, B. (2020). Online mental health services in China during the COVID-19 outbreak. The Lancet Psychiatry, 7(4), E17-E18. https://doi.org/10.1016/S2215-0366(20)30077-8

Meydan, C. H., \& Sesen, H. (2011). Structural equation modeling AMOS applications. Ankara: Detay Publishing.

Nguyen, H. C., Nguyen, M. H., Do, B. N., Tran, C. Q., Nguyen, T. T. P., Pham, K. P., Pham, L. V., Tran, K. V., Duong, T. T., Tran, T. V., Duong, T. H., Nguyen, T. T., Nguyen, Q. H., Hoang, T. M., Nguyen, K. T., Pham, T. T., Yang, S. H., Chao, J., \& Duong, T. V. (2020). People with suspected covid-19 symptoms were more likely depressed and had lower health-related quality of life: The potential benefit of health literacy. Journal Clinical Medical, 9(965), 1-18. https://doi.org/10.3390/jcm9040965

Polit, D. F., \& Beck, C. T. (2018). Essentials of nursing research: Appraising evidence for nursing practice (9th ed.). Wolters Kluwer.

Rubin, G. J., Potts, H. W. W., \& Michie, S. (2010). The impact of communications on swine flu (influenza A H1N1v) on public responses to the outbreak: Results of 36 national telephone surveys in the UK. Health Technology Assess, 14(34), 183-266. https://doi.org/10.3310/hta14340-03

Schofield, P. E., Stockler, M. R., Zannino, D., Tebbutt, N. C., Price, T. J., Simes, R. J., Wong, N., Pavlakis, N., Ransom, D., Moylan, E., Underhill, C., Wyld, D., Burns, I., Ward, R., Wilcken, N., \& Jefford, M. (2016). Hope, optimism and survival in a randomised trial of chemotherapy for metastatic colorectal cancer. Supportive Care in Cancer, 24(1), 401-408. https://doi.org/10.1007/s00520-015-2792-8

Şahin, M. (2020). Impact of weather on COVID-19 pandemic in Turkey. The Science of the Total Environment, 728, 138810. https:// doi.org/10.1016/j.scitotenv.2020.138810

Şencan, H. (2005). Reliability and validity in social and behavioral measures. Seçkin Publishing.

Tavşancıl, E. (2010). Measurement of attitudes and data analysis with SPSS. Nobel Publication Distribution.

Taylor, S. (2019). The psychology of pandemics: Preparing for the next global outbreak of infectious disease. Cambrigde Scholars Publishing.

Waltz, C. F., Strickland, O. L., \& Lenz, E. R. (Eds.). (2010). Measurement in nursing and health research. Springer publishing company.

Wang, S., Xu, X., Zhou, M., Chen, T., Yang, X., Chen, G., \& Gong, Q. (2017). Hope and the brain: Trait hope mediates the protective role of medial orbitofrontal cortex spontaneous activity against anxiety. NeuroImage, 157, 439-447. https://doi.org/10.1016/j. neuroimage.2017.05.056

Wheaton, M. G., Deacon, B. J., McGrath, P. B., Berman, N. C., \& Abramowitz, J. S. (2012). Dimensions of anxiety sensitivity in the anxiety disorders: Evaluation of the ASI-3. Journal of Anxiety Disorders, 26(3), 401-408. https://doi.org/10.1016/j.janxdis. 2012.01.002

World Health Organization. (2021). Coronavirus disease 2019 (COVID-19): situation report, 82. Access address: https://www. 
who.int/emergencies/diseases/novel-coronavirus-2019 Access Date: 04 October 2021.

Uysa, M. T., \& Eren, G. T. (2020). Discrimination Against the Elderly on Social Media during the COVID-19 Epidemic: Twitter Case. Turkish Studies, 15(4), 1147-1162. https://doi.org/10.7827/Turki shStudies.44396

Van Bortel, T., Basnayake, A., Wurie, F., Jambai, M., Koroma, A. S., Muana, A. T., ... Nellums, N. B. (2016). Psychosocial efects of an Ebola outbreak at individual, community and international levels. Bull World Health Organ. 94(3), 210-214. https://doi.org/ 10.2471/BLT.15.158543
Yip, W. C. M., Hsiao, W., Meng, Q., Chen, W., \& Sun, X. (2010). Realignment of incentives for health-care providers in China. The Lancet, 375(9720), 1120-1130. https://doi.org/10.1016/S01406736(10)60063-3

Publisher's Note Springer Nature remains neutral with regard to jurisdictional claims in published maps and institutional affiliations. 